Published in final edited form as:

Sex Transm Infect. 2018 December ; 94(8): 607-610. doi:10.1136/sextrans-2017-053292.

\title{
Individual and partnership factors associated with anticipated versus actual partner notification following STI diagnosis among men who have sex with men and/or with transgender women in Lima, Peru
}

\author{
Hannan M Braun ${ }^{1,2}$, Eddy R Segura ${ }^{2,3}$, Jordan E Lake ${ }^{2,4}$, Monica Gandhi ${ }^{5}$, Jessica Rios ${ }^{6}$, \\ Manuel V Villaran ${ }^{6}$, Jorge Sanchez ${ }^{6,7,8}$, Javier R Lama ${ }^{6,7}$, and Jesse L Clark ${ }^{2}$ \\ ${ }^{1}$ School of Medicine, University of California, San Francisco, San Francisco, California, USA \\ 2Department of Medicine, Division of Infectious Diseases, South American Program in HIV \\ Prevention Research, David Geffen School of Medicine, University of California, Los Angeles, \\ California, USA \\ ${ }^{3}$ Escuela de Medicina, Universidad Peruana de Ciencias Aplicadas, Lima, Peru \\ ${ }^{4}$ Department of Internal Medicine, Division of Infectious Diseases, McGovernMedical School at \\ UTHealth, Houston, Texas, USA \\ ${ }^{5}$ Division of HIV, Infectious Diseases and Global Medicine, University of California, San Francisco, \\ California, USA \\ ${ }^{6}$ Asociación Civil Impacta Salud y Educación, Lima, Peru \\ ${ }^{7}$ Department of Global Health, University of Washington, Seattle, Washington, USA \\ ${ }^{8}$ Centro de Investigaciones Tecnológicas, Biomédicas y Medioambientales, Lima, Peru
}

\begin{abstract}
Objectives-A detailed understanding of intentions and practices related to partner notification (PN) following STI diagnosis can improve control strategies. We assessed participant-level and partner-level factors guiding notification behaviour among men who have sex with men and/or
\end{abstract}

\footnotetext{
Correspondence to: Hannan M Braun, School of Medicine, University of California, San Francisco, CA 94143, USA; Hannan.Braun@ucsf.edu.

Contributors JLC, ERS and HMB: conceptualised the analysis. JLC, ERS, JR, MVV, JS and JRL: assisted with study design and implemented the study procedures including data collection. HMB and ERS: conducted the statistical analysis. HMB, JLC, ERS, JEL and MG: interpreted the results. HMB: drafted the manuscript. All authors: edited and approved the final version of the manuscript.

Competing interests None declared.

Patient consent Obtained.

Ethics approval The study procedures were approved by the UCLA Office for Human Research Participant Protection (for ClinicalTrials.gov NCT01720654: IRB11-003095; for ClinicalTrials.gov NCT01720641: IRB 11-003105), the Asociacion Civil Impacta Comite de Bioetica (for ClinicalTrials.govNCT01720654: Certificate 0053-2012-CE; for ClinicalTrials.govNCT01720641: 0052-2012-CE), and the US Naval Medical Research Unit-6 (for ClinicalTrials.gov NCT01720654: Protocol HRPP

NAMRU6.2012.0033), and registered with the Peruvian Instituto Nacional de Salud. Written informed consent was obtained from all study participants.

Provenance and peer review Not commissioned; externally peer reviewed.
} 
with transgender women (MSM-TW) in Lima, Peru, including discordances between anticipated and actual notification.

Methods-Men newly diagnosed with gonorrhoea, chlamydia and/or syphilis between 2012 and 2014 reported recent partners' characteristics, anticipated PN practices, and actual PN outcomes following diagnosis. Generalised estimating equation Poisson regression analyses assessed factors guiding PN outcomes.

Results-Participants $(\mathrm{n}=150)$ predominantly identified as homosexual $(70 \%)$ and moderno (versatile sexual role, 55\%); 55\% of partners $(\mathrm{n}=402)$ were casual. Among all sexual partners, $35 \%$ were notified of the STI diagnosis, though only $51 \%$ of predicted PN occurred and $26 \%$ of actual notifications were unanticipated. $47 \%$ of participants notified no partners, while $24 \%$ notified all partners. PN was more common with stable versus casual (adjusted prevalence ratio (aPR), 95\% CI: $0.53,0.39$ to 0.73 ) or commercial (aPR, 95\% CI: $0.38,0.12$ to 1.21 ) partners, and among participants who perceived PN as normative among their peers (aPR, 95\% CI: 1.96, 1.37 to 2.82). A trend towards greater notification following condom-protected intercourse was observed (aPR, 95\% CI: 1.33, 0.98 to 1.81). PN frequency did not differ by type of STI diagnosed. Anticipated notification predicted actual notification (aPR, 95\% CI: 1.67, 1.19 to 2.33 ) only imperfectly: 81 (54\%) participants' PN practices did not match their anticipated behaviour. Successful notification despite anticipated silence (40 participants, 63 partners) was associated with stable partnerships and a normative perception of PN. Non-notification despite intention (43 participants, 73 partners) frequently occurred among participants reporting exclusively oral sex with the partner or with partners identified as activo (insertive role).

Conclusions-Anticipated notification imperfectly reflects actual PN behaviour. Future interventions to improve PN among MSM-TW in Peru need to acknowledge partnership contexts.

\section{OBJECTIVES}

Partner notification (PN) is a critical component of sexually transmitted infection (STI) control that targets public health efforts to high-risk sexual networks. ${ }^{1}$ Given the burden of STIs among men who have sex with men (MSM) and/or with transgender women (TW) in Latin America, ${ }^{2}$ there is a need to understand how PN operates, and can be addressed, in specific partnership contexts.

Our group has studied different aspects of PN among MSM and TW in Peru, including the effectiveness of expedited partner therapy. ${ }^{3}$ Formative research, conducted largely in 20112012, detailed the acceptability of new PN tools, ${ }^{4}$ and explored perceived source of STIs among STI-diagnosed MSM. ${ }^{5}$ Our recent mixed-methods analysis found anticipated PN more likely for main partners and for non-HIV STIs. ${ }^{6}$ However, anticipated behaviour is influenced by social desirability bias, and practices may change post diagnosis. Most PN outcomes studies report retrospective data on the proportion of partners notified or reporting to a study clinic. ${ }^{7}$ However, this metric misses information on partner-specific factors and often fails to compare notification outcomes with anticipated behaviour.

We evaluated participant-level and partner-level factors guiding notification following STI diagnosis among MSM in Lima, Peru, including discordances between anticipated and actual partner-specific notification. 


\section{METHODS}

\section{Participants and recruitment}

From August 2012 to June 2014, MSM and TW newly diagnosed with gonorrhoea (NG), chlamydia (CT), and/or syphilis were screened for eligibility in two trials of PN and treatment (ClinicalTrials.gov NCT01720654, NCT01720641). (Since formative research found significant differences in social contexts of notification for HIV versus curable STIs, these trials focused only on NG/CT and syphilis infection.) Eligibility for screening included: (1) age $\geq 18$ years; (2) male sex assigned at birth and (3) sexual contact with a man or TW in the previous year.

We restricted our analysis to participants in the control arms to limit the effects of any experimental interventions. As few participants self-identified as TW and the number of cisgender female partners reported was low, only men reporting sexual encounters with men or TW (MSM-TW) were included in this analysis.

\section{Study procedures}

All participants completed a computer-assisted self-administered (CASI) behavioural survey, underwent a physical examination, completed HIV/STI testing and received pretest and post-test counselling (including standard PN recommendations). Participants received STI treatment and 10 Nuevos soles (US\$3.50) for transportation.

\section{Data collection}

At screening, we collected information on sociodemographics, sexual orientation/gender identity, and sexual role (activo (insertive role during anal intercourse), pasivo (receptive) and moderno (versatile)). ${ }^{8}$ Participants identified each of their three most recent sexual partners with a pseudonym or label to assist with future recall and reported characteristics of each partner, including relationship type (stable, casual, anonymous, commercial sex (provider or client)), ${ }^{6}$ partner-specific sexual practices, and partner gender identity/sexual orientation and sexual role.

Four-point Likert scales assessed attitudes about PN importance, perceived norms surrounding PN and anticipated likelihood of notifying each named partner. At the 14-day follow-up visit, participants were reminded of the pseudonyms and asked to report partnerspecific notification outcomes.

\section{Sample size and power calculations}

Sample size calculations for the clinical trials were based on notification outcomes from previous observational studies of Peruvian men and women diagnosed with an STI, as detailed in their respective manuscripts. ${ }^{69}$

\section{Data analysis}

The main outcome was self-reported notification for each recent partner at 14-day follow-up. A secondary outcome explored 'PN discordance', or notification events that did not align 
with anticipated behaviour (ie, notification of a partner who was not expected to be notified, or failure to notify a partner despite anticipating notification).

We calculated descriptive summaries of participant and partner characteristics. Prevalence ratios were calculated using generalised estimating equation models to adjust for clustering to estimate factors associated with notification. Variables were selected for the model using conceptual reasoning, as selection based solely on significance testing was limited by collinearity and small sample size. We repeated this approach to assess factors associated with PN discordance. All analyses were performed with Stata V.14.0 (StataCorp, College Station, Texas, USA).

\section{RESULTS}

We analysed data from 150 MSM-TW recently diagnosed with syphilis, NG, and/or CT (table 1). Participants generally agreed it was important to notify sexual partners after being diagnosed with NG/CT (83\%), syphilis (77\%) or HIV (78\%). However, most believed that few of their friends would notify a stable partner if diagnosed with the same STIs (NG/CT: 12\%, syphilis: $15 \%$, and HIV: $19 \%$ ). The median number of sexual partners in the prior month was 2 (IQR 1 to 4 ).

Participants in our analysis listed 402 non-anonymous partners and anticipated notifying $38 \%$ of these partners (table 1). Multi-partner participants predominantly listed partners of the same type: all casual (41.4\%), all stable (24.8\%) or all commercial clients $(6.0 \%) ; 27.8 \%$ reported mixed partnership types. At follow-up, 35\% of all partners had been notified (per participant self-report), including $53 \%$ of stable, $25 \%$ of casual, and $11 \%$ of commercial partners. (Though excluded from our analysis, cisgender female partners $(n=16)$ were notified at a similar rate (31\%).) Forty-seven per cent of participants did not notify any recent partner, $24 \%$ notified all partners, and $29 \%$ notified only certain partners.

Notification was more frequent for stable compared with casual (adjusted prevalence ratio (aPR), 95\% CI: $0.53,0.39$ to 0.73 ) or commercial (aPR, 95\% CI: $0.38,0.12$ to 1.21 ) partners. A trend emerged towards notifying partners with whom participants had used condoms (aPR, 95\% CI: 1.33, 0.98 to 1.81). Notification frequency did not differ according to age or type of STI, but was associated with perceived community norms supporting notification (aPR, 95\% CI: 1.96, 1.37 to 2.82 ).

In looking at discrepancies between anticipated and actual notification, $51 \%$ of predicted notifications occurred, while $26 \%$ of successful notifications were unanticipated. Anticipated notification predicted actual notification (aPR, 95\% CI: 1.67, 1.19 to 2.33), though only imperfectly as $54 \%$ of all participants did not follow through with their expected notification behaviour. Forty-three participants did not notify 73 partners despite notification intention, and 40 participants notified 63 partners despite anticipated silence. Unanticipated notification was more frequent with stable as opposed to casual (crude PR (cPR), 95\% CI: $0.38,0.24$ to 0.58 ) or commercial (cPR, 95\% CI: $0.09,0.18$ to 0.51 ) partners, and by participants describing community norms supporting notification (cPR, 95\% CI: $2.58,1.45$ to 4.59 ). Failure to notify (despite intent) was more frequently reported 
with casual partners (cPR, 95\% CI: 1.52, 1.02 to 2.27), exclusively oral sex partners (cPR, 95\% CI: $1.67,1.14$ to 2.45 ) and activo as opposed to pasivo (cPR, 95\% CI: 0.68, 0.43 to 1.06 ) or moderno (cPR, $95 \%$ CI: $0.67,0.44$ to 1.00 ) partners.

\section{DISCUSSION}

Our analysis details the association of individual-level and dyad-level factors with notification practices (and their discordance with anticipated behaviour) following STI diagnosis among MSM-TW in Lima, Peru. These findings affirm the centrality of partnership type in guiding PN, and identify discrepancies between anticipated PN behaviour and actual outcomes. Taken together, our findings reveal how differences in individual and partnership characteristics, risk perceptions, and social norms result in distinct patterns of PN among MSM-TW. Knowledge of these factors can help tailor new PN modalities to high-risk populations in Latin America.

We observed several unexpected findings. Notification may be more likely following condom-protected sex, despite the reduced risk of STI transmission. However, participants may be employing both condom use and PN as dual strategies to protect the health of their partners. That PN frequency did not differ by STI diagnosis in this study of only NG/CT and syphilis affirms our formative research differentiating HIV from other STIs, which were generally considered interchangeable.

Our findings are among the first to address discordance between anticipated and actual notification behaviour. Both discordant and concordant notification results followed similar patterns, highlighting the primacy of partnership type. The disproportionate failure to notify activo (insertive) partners may reflect power dynamics within Peruvian sexual partnerships where the insertive partner is considered masculine, virile, and potentially abusive. ${ }^{68}$ These findings suggest that patterns of communication and trust are more powerful determinants of notification than behavioural intention. Psychosocial and behavioural studies on PN emphasise that self-efficacy, social influence, and relationship quality all determine dyadic behaviour. ${ }^{710}$ To our knowledge, however, there have not been behavioural studies addressing intent versus actual PN for MSM, and a need remains to identify the psychosocial factors that result in PN discordance following STI diagnosis.

Several limitations to our study exist. All partner characteristics, as well as PN outcomes, were reported by participants rather than by partners, generating uncertainty regarding partner data. In classifying participants, the baseline survey included self-identified sexual orientation and gender identity options within the same multiple-choice question, collapsing the two variables into a uniform category, possibly misclassifying TW. Finally, the original study was not powered to detect associations for our secondary outcome (PN discordance), so we chose to focus on descriptive and bivariate analyses for this outcome. Despite these limitations, our data provide important information to tailor future PN interventions.

\section{CONCLUSION}

Our results highlight how individual attitudes, partnership characteristics, biological factors, and social structures all inform PN processes among MSM-TW in Peru following an STI 
diagnosis. Given that anticipated notification is only an imperfect predictor of actual PN outcomes, future mixed-methods research may better elucidate which factors impact the gap between intention and action to improve future PN interventions for vulnerable populations.

\section{Acknowledgments}

The authors thank the participants who contributed their time and experiences. The authors acknowledge the staff at Asociación Civil Impacta Salud y Educación for their assistance throughout the study. HMB is a Doris Duke International Clinical Research Fellow.

Funding This research was supported by the National Institutes of Health grants R25 MH087222 (South American Program in HIV Prevention Research; PI: J. Clark), K23 MH 084611 (PI: J. Clark), K23 AI 110532 (PI: J. Lake) and R21 MH 092322 (PI: T. Coates). This work was supported in part by the Doris Duke Charitable Foundation through a grant supporting the Doris Duke International Clinical Research Fellows Program at the University of California, San Francisco.

\section{References}

1. Bell G, Potterat J. Partner notification for sexually transmitted infections in the modern world: a practitioner perspective on challenges and opportunities. Sex Transm Infect. 2011; 87(Suppl 2):ii34-ii36. [PubMed: 22110152]

2. Vega M, Chinarro MP. Análisis de la situación epidemiológica del VIH/SIDAen el Perú 2013. Lima, Peru: Ministerio de Salud de Salud, Dirección General de Epidemiología; 2013.

3. Clark JL, Segura ER, Oldenburg CE, et al. Expedited partner therapy (EPT) increases the frequency of partner notification among MSM in Lima, Peru: a pilot randomized controlled trial. BMC Med. 2017; 15:94. [PubMed: 28468648]

4. Clark JL, Segura ER, Perez-Brumer AG, et al. Potential impact and acceptability of Internet partner notification for men who have sex with men and transgender women recently diagnosed as having sexually transmitted disease in Lima, Peru. Sex Transm Dis. 2014; 41:43-5. [PubMed: 24326581]

5. Blair CS, Segura ER, Perez-Brumer AG, et al. Sexual orientation, gender identity and perceived source of infection among men who have sex with men (MSM) and transgender women (TW) recently diagnosed with HIV and/or STI in Lima, Peru. AIDS Behav. 2016; 20:2178-85. [PubMed: 26767533]

6. Clark JL, Perez-Brumer AG, Segura ER, et al. Anticipated notification of sexual partners following std diagnosis among men who have sex with men and transgender women in lima, peru: A mixed methods analysis. PLoS One. 2016; 11:e0163905. [PubMed: 27685158]

7. Nuwaha F, Kambugu F, Nsubuga PS. Factors influencing sexual partner referral for sexually transmitted diseases in Uganda. Sex Transm Dis. 1999; 26:483-9. [PubMed: 10494941]

8. Clark J, Salvatierra J, Segura E, et al. Moderno love: sexual role-based identities and HIV/STI prevention among men who have sex with men in Lima, Peru. AIDS Behav. 2013; 17:1313-28. [PubMed: 22614747]

9. Clark JL, Long CM, Giron JM, et al. Partner notification for sexually transmitted diseases in Peru: knowledge, attitudes, and practices in a high-risk community. Sex Transm Dis. 2007; 34:309-13. [PubMed: 17016236]

10. Fortenberry JD, Brizendine EJ, Katz BP, et al. The role of self-efficacy and relationship quality in partner notification by adolescents with sexually transmitted infections. Arch Pediatr Adolesc Med. 2002; 156:1133-7. [PubMed: 12413343] 
Table 1

Participant and partner characteristics and their association with partner notification behaviour among MSM and/or with transgender women diagnosed with STI, Lima, Peru, 2012 to 2014

\begin{tabular}{|c|c|c|c|c|}
\hline & & \multirow[b]{2}{*}{$\begin{array}{l}\text { Factors } \\
\text { associated with } \\
\text { actual partner } \\
\text { notification } \\
(n=139 / 402)\end{array}$} & \multicolumn{2}{|l|}{ PN discordance } \\
\hline & & & Unanticipated notification $(n=63 / 249)$ & $\begin{array}{l}\text { Non- } \\
\text { notification } \\
\text { despite intent } \\
(n=73 / 153)\end{array}$ \\
\hline Variable & Category labels (\%) & $\begin{array}{l}\text { Adjusted PR } \\
(95 \% \text { CI })\end{array}$ & Crude PR (95\% CI) & $\begin{array}{l}\text { Crude PR } \\
(95 \% \text { CI })\end{array}$ \\
\hline \multicolumn{5}{|l|}{ Participant characteristics } \\
\hline Age $(n=150)$ & In years (mean: 29 years) & $\begin{array}{l}0.99(0.97 \text { to } \\
1.02)\end{array}$ & $0.98(0.94$ to 1.01$)$ & $\begin{array}{l}0.98(0.94 \text { to } \\
1.01)\end{array}$ \\
\hline \multirow[t]{2}{*}{ Education $(n=150)$} & $\begin{array}{l}\text { Less than full high school } \\
(13.3)\end{array}$ & Ref & Ref & Ref \\
\hline & $\begin{array}{l}\text { High school degree or } \\
\text { higher (86.7) }\end{array}$ & $\begin{array}{l}1.12(0.63 \text { to } \\
1.98)\end{array}$ & $2.18(0.56$ to 8.44$)$ & $\begin{array}{l}1.51(0.68 \text { to } \\
3.36)\end{array}$ \\
\hline \multirow[t]{3}{*}{ Sex role $(n=149)$} & Activo (17.5) & Ref & - & - \\
\hline & Pasivo (27.5) & $\begin{array}{l}0.75(0.44 \text { to } \\
1.27)\end{array}$ & - & - \\
\hline & Moderno (55.0) & $\begin{array}{l}1.07(0.70 \text { to } \\
1.65)\end{array}$ & - & - \\
\hline \multirow[t]{3}{*}{ STI(s) diagnosed $(n=150)$} & NG/CT (42.0) & Ref & - & - \\
\hline & Syphilis (46.0) & $\begin{array}{l}0.85(0.56 \text { to } \\
1.27)\end{array}$ & - & - \\
\hline & $\begin{array}{l}\text { NG/CT and syphilis } \\
\text { coinfection (12.0) }\end{array}$ & $\begin{array}{l}0.95(0.56 \text { to } \\
1.62)\end{array}$ & - & - \\
\hline \multicolumn{2}{|c|}{$\begin{array}{l}\text { Notification perceived as community norm (stable partners) } \\
\text { (12.7) }\end{array}$} & $\begin{array}{l}1.96(1.37 \text { to } \\
2.82)\end{array}$ & $2.58(1.45$ to 4.59$)$ & $\begin{array}{l}0.62(0.34 \text { to } \\
1.14)\end{array}$ \\
\hline \multicolumn{5}{|l|}{ Partnership characteristics } \\
\hline \multirow[t]{3}{*}{ Type of partnership ${ }^{*}(\mathrm{n}=398)$} & Stable (37.9) & Ref & Ref & Ref \\
\hline & Casual (55.3) & $\begin{array}{l}0.53(0.39 \text { to } \\
0.73)\end{array}$ & $0.38(0.24$ to 0.58$)$ & $\begin{array}{l}1.52(1.02 \text { to } \\
2.27)\end{array}$ \\
\hline & $\begin{array}{l}\text { Commercial sex client } \\
(6.8)\end{array}$ & $\begin{array}{l}0.38(0.12 \text { to } \\
1.21)\end{array}$ & $0.09(0.18-0.51)$ & $\begin{array}{l}1.42(0.53 \text { to } \\
3.83)\end{array}$ \\
\hline \multirow{4}{*}{$\begin{array}{l}\text { Partner sexual orientation/ } \\
\text { gender identity }(\mathrm{n}=379)\end{array}$} & Homosexual (66.2) & Ref & - & - \\
\hline & Bisexual (24.0) & $\begin{array}{l}0.91(0.61 \text { to } \\
1.35)\end{array}$ & - & - \\
\hline & Heterosexual (8.7) & $\begin{array}{l}0.94(0.58 \text { to } \\
1.52)\end{array}$ & - & - \\
\hline & Transgender (1.1) & $\begin{array}{l}0.69(0.19 \text { to } \\
2.51)\end{array}$ & - & - \\
\hline Sexual role $(n=388)$ & Activo (34.0) & - & Ref & Ref \\
\hline
\end{tabular}

Sex Transm Infect. Author manuscript; available in PMC 2019 December 01. 


\begin{tabular}{|c|c|c|c|c|}
\hline & & \multirow[b]{2}{*}{$\begin{array}{l}\text { Factors } \\
\text { associated with } \\
\text { actual partner } \\
\text { notification } \\
(n=139 / 402)\end{array}$} & \multicolumn{2}{|l|}{ PN discordance } \\
\hline & & & Unanticipated notification $(n=63 / 249)$ & $\begin{array}{l}\text { Non- } \\
\text { notification } \\
\text { despite intent } \\
(\mathbf{n}=\mathbf{7 3 / 1 5 3 )}\end{array}$ \\
\hline \multirow[t]{3}{*}{ Variable } & Category labels (\%) & $\begin{array}{l}\text { Adjusted PR } \\
(95 \% \text { CI })\end{array}$ & Crude PR (95\% CI) & $\begin{array}{l}\text { Crude PR } \\
(\mathbf{9 5 \%} \text { CI })\end{array}$ \\
\hline & Pasivo (22.9) & - & $1.13(0.70$ to 1.82$)$ & $\begin{array}{l}0.68(0.43 \text { to } \\
1.06)\end{array}$ \\
\hline & Moderno (43.0) & - & $1.04(0.65$ to 1.68$)$ & $\begin{array}{l}0.67(0.44 \text { to } \\
1.00)\end{array}$ \\
\hline \multirow[t]{2}{*}{ Oral sex only $(n=402)$} & No (91.3) & - & Ref & Ref \\
\hline & Yes (8.7) & - & 0.88 (0.47 to 1.66$)$ & $\begin{array}{l}1.67(1.14 \text { to } \\
2.45)\end{array}$ \\
\hline \multirow[t]{2}{*}{ Condomless anal sex $(n=402)$} & Yes (51.0) & Ref & - & - \\
\hline & No (49.0) & $\begin{array}{l}1.33(0.98 \text { to } \\
1.81)\end{array}$ & - & - \\
\hline \multirow{2}{*}{$\begin{array}{l}\text { Anticipated PN outcome } \\
(\mathrm{n}=402)\end{array}$} & Non-notification $(61.9 \%)$ & Ref & N/A & N/A \\
\hline & Notification (38.1) & $\begin{array}{l}1.67(1.19 \text { to } \\
2.33)\end{array}$ & N/A & N/A \\
\hline
\end{tabular}

